
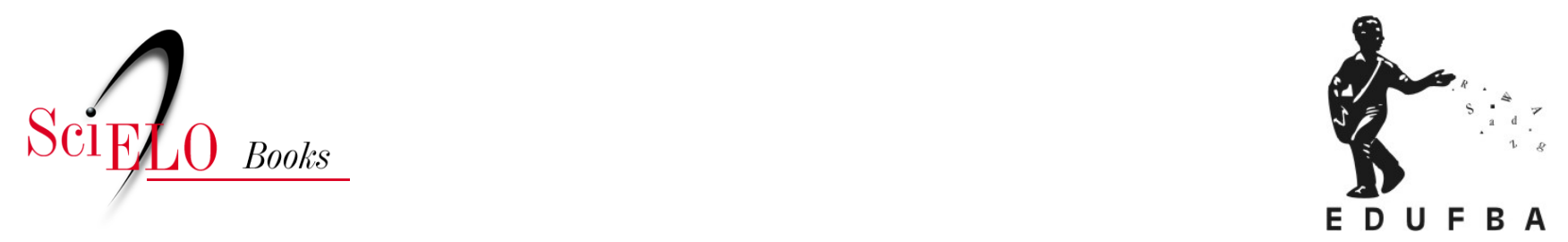

\title{
2 - Contribuições do referencial bourdieusiano e da abordagem sócio-histórica para a análise de políticas de saúde
}

\author{
Sandra Garrido de Barros
}

\section{SciELO Books / SciELO Livros / SciELO Libros}

BARROS, S.G. Contribuições do referencial bourdieusiano e da abordagem sócio-histórica para a análise de políticas de saúde. In: Política Nacional de Aids: construção da resposta governamental à epidemia HIV/aids no Brasil [online]. Salvador: EDUFBA, 2018, pp. 28-39. ISBN 978-85-232-2030-3. https://doi.org/10.7476/9788523220303.0003.

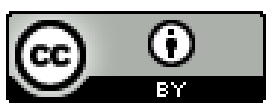

All the contents of this work, except where otherwise noted, is licensed under a Creative Commons Attribution 4.0 International license.

Todo o conteúdo deste trabalho, exceto quando houver ressalva, é publicado sob a licença Creative Commons Atribição 4.0. 



\section{Contribuições do referencial bourdieusiano e da abordagem sócio-histórica para a análise de políticas de saúde}

Para reconstruir a dinâmica do jogo social, do qual emergiram as respostas à epidemia da aids no Brasil, foi adotado o referencial teórico da sociologia reflexiva de Bourdieu (1996, 2001, 2008), apoiado na proposta de Pinell e colaboradores (2002) e Pinell (2010) para a análise sociológica de políticas públicas.

\section{Conceitos fundamentais}

O conceito de espaço social foi adotado para estudar a estrutura e a dinâmica de relações dos agentes engajados em lutas concorrentes em torno de um objetivo comum (PINELL et al., 2002), no caso específico desse estudo, a luta contra a epidemia da aids. O espaço aids foi analisado a partir da compreensão do seu processo de emergência, desenvolvimento e transformação.

A ideia de diferença está no fundamento do conceito de "espaço social”. A distribuição dos agentes no espaço social se dá de acordo com as diversas espécies de capital e em particular com o "capital cultural”, “o capital econômico", “o volume de capital global” e a "trajetória social”, mas também com os capitais político, social, simbólico e mesmo o capital burocrático. As diferenças entre essas posições correspondem a diferenças nas disposições (habitus) ${ }^{8}$ e nas tomadas de posição. Ou seja, a cada

8 Habitus é o princípio gerador e unificador das práticas. Representa as características intrínsecas e relacionais de uma posição em um estilo de vida (escolhas de pessoas, bens e práticas), gerando práticas distintas e distintivas. É o senso prático do que se deve fazer em uma 
classe de posições corresponde a uma classe de habitus - ou de gostos produzidos pelos condicionamentos sociais associados à condição correspondente e, pela intermediação desses habitus e de suas capacidades geradoras. (BOURDIEU, 1996)

O capital cultural é constituído por um conjunto de bens simbólicos relacionados aos conhecimentos incorporados - ser competente em um domínio do saber, ser culto, ter bom domínio da linguagem -, à posse de bens culturais - livros, dicionários, instrumentos, máquinas - e, no seu estado institucionalizado, aos títulos, diplomas e à aprovação em concursos, que nada mais são que a objetivação do reconhecimento de competências pelo Estado. O capital cultural é resultado de um trabalho contínuo de aprendizagem e acumulação. Sua aquisição demanda tempo e, portanto, bens materiais, geralmente estando relacionado com o capital econômico do qual seria uma espécie de conversão. Assim, o capital cultural é constituído a partir da interação entre os espaços familiar e escolar, de modo que agentes com o mesmo capital escolar podem possuir capitais culturais diferentes em função do seu capital cultural herdado. (BOURDIEU, 2008)

O capital social é um capital de relações, trata-se dos ganhos associados à existência de uma rede de conexões atuais ou potenciais, mais ou menos institucionalizadas, de pertencimento a um grupo. O capital social tende a ser uma espécie de multiplicador de seus poderes por um efeito de agregação simbólica. (BOURDIEU, 1980)

O capital simbólico é uma forma de capital que nasce da relação entre uma espécie qualquer de capital e os agentes socializados de maneira a conhecer e reconhecer essa espécie de capital. Para Bourdieu (2012), mesmo nos casos em que a espécie de capital é mais próxima do mundo físico, não há efeito físico que não se acompanhe de efeito simbólico, de modo que o conceito de capital simbólico permite fazer uma teoria materialista do simbólico. Nesse sentido, o capital econômico não se trata apenas da riqueza. Há um reconhecimento relacionado à riqueza que faz

dada situação. Corresponde às disposições dos agentes, seus esquemas de percepção, produzidos pela história coletiva, modificados pela história individual de cada um, e incorporados de forma inconsciente. (BOURDIEU, 1996, 2008) 
com que a força econômica exerça também um efeito simbólico além da riqueza dada pelo reconhecimento.

O capital simbólico é uma propriedade qualquer (de qualquer tipo de capital, físico, econômico, cultural, social), percebida pelos agentes sociais em cujas categorias de percepção são tais que eles podem entendê-las (percebê-las) e reconhecê-las, atribuindo-lhes valor. (BOURDIEU, 1996, p. 107)

É portanto, a forma como qualquer tipo de capital é percebido pelos agentes do espaço social.

O capital político está relacionado à capacidade de mobilização de um agente, é uma espécie de capital social e simbólico, obtido a título pessoal, resultado de um capital pessoal de notoriedade e popularidade - ser conhecido e reconhecido -, ou por delegação de uma organização detentora desse tipo de capital, como partidos ou sindicatos. À medida que a política profissionaliza-se, a luta é reservada aos profissionais e às grandes unidades de produção e difusão, excluindo os "profanos”, de modo que a objetivação do capital político foi realizada a partir do acesso a posições na política tradicional, ou seja, em postos no seio de um partido e nos organismos de poder e em toda a rede de empresas em simbiose com esses organismos, bem como na participação em cargos eletivos. (BOURDIEU, 2001; MATONTI; POUPEAU, 2004)

O capital militante cobre um conjunto de saberes e práticas, mobilizados durante as ações coletivas, as lutas inter ou intrapartidárias, é incorporado sob a forma de técnicas, de disposições de agir, intervir ou simplesmente obedecer. Este capital é passível de ser convertido em outros universos, podendo facilitar certas reconversões capazes de manter ou transformar a posição de um indivíduo ou de um grupo na estrutura social. (MATONTI; POUPEAU, 2004) Sob certas condições, o capital militante pode ser uma via de acesso ao capital político, quando, por exemplo, um agente é associado a personificação e divulgação de uma ação que permite reconverter sua notoriedade militante adquirida em investimentos políticos mais institucionalizados, como os partidos políticos. (GARCIA, 2005) 
No espaço social, podem ser identificados subespaços constituídos por redes de relações entre agentes e instituições com leis próprias, autonomia relativa e um habitus comum, no qual existem lutas específicas que fazem sentido aos seus integrantes, ao que Bourdieu denomina “campo".

O espaço aids foi considerado um espaço onde se articulam agentes - dos campos médico, científico, burocrático, político e do espaço associativo ou militante ${ }^{9}$ - engajados na luta pela organização da resposta à epidemia da aids. (PINELL et al., 2002)

Para a análise do espaço associativo ou militante, foi adotado o modelo de análise dos movimentos sociais em saúde proposto por Brown e colaboradores (2004) a partir da teoria dos movimentos sociais, dividindo-os em três categorias: movimentos de acesso à saúde, que lutam por acesso equânime à assistência médica e para a implementação da oferta de serviços de assistência à saúde, movimentos de saúde circunscritos a grupos específicos, direcionados à luta contra as desigualdades em saúde baseadas em raça, etnia, gênero, classe e/ou diferenças sexuais, e movimentos desaúde incorporados, que se direcionam para a doença, desafiando a ciência em relação a etiologia, diagnóstico, tratamento e prevenção.

A Saúde Coletiva, no momento da sua gênese, foi compreendida enquanto um espaço social influenciado de forma importante pelo saber e práticas do campo médico - do qual surgiu e no qual seus agentes ainda guardam raízes e identidades -, mas em busca de autonomia e identidade própria, cuja institucionalização se dá no âmbito dos campos científico e burocrático, além da relação estreita com os campos político e do poder, tendo como projeto político a Reforma Sanitária. (VIEIRA-DA-SILVA;

Os agentes pertencentes às associações específicas de luta contra a aids, que no Brasil são conhecidas como ONGs/aids, optam pelo uso do termo ativismo ao invés de militância. Nessa perspectiva, o ativismo seria uma nova maneira de engajamento, em contraposição à militância característica das ONGs do início dos anos 1980 no Brasil, que têm como ponto de partida problemas sociais ou causas públicas e estavam baseados no que Weber define como ética da convicção. O ativismo estaria baseado na experiência individual e íntima, no caso, o viver com HIV/aids, como condição de mobilização e de luta, resultando em um engajamento pessoal, em necessidades urgentes que demandam uma resolução no presente e centrado na ética da responsabilidade, conforme definida por Weber. Ou seja, o ativismo não teria um projeto de mudança da sociedade como um todo, mas da garantia de determinadas condições. (SILVA, 1999) 
PINELL, 2013) Assim, a burocracia estatal da saúde ligada à Política Nacional de DST/Aids é componente desses dois espaços, dentro dos quais representa o campo burocrático.

É no âmbito do Estado que se formulam as políticas de saúde, sendo indispensável pensar o Estado e sua conformação para a análise das suas respostas a problemas sociais específicos.

Analisando criticamente diversas teorias sobre o Estado, Bourdieu (1996) considerou que, para melhor compreendê-lo, seria necessário investigar o campo burocrático. Considera os burocratas não como usurpadores do universal, mas que se impõe a eles uma "referência obrigatória aos valores de neutralidade e de devotamento desinteressado ao bem público.” (BOURDIEU, 1996, p. 122) Apesar de a lei do campo burocrático ser o serviço público, o universal, os campos onde o desinteresse é a norma, não são regidos apenas pelo desinteresse. Este desinteresse é recompensado de alguma forma. O que está ausente é o interesse econômico, mas não significa que outras formas de interesse não estejam envolvidas, beneficiando-se de um lucro simbólico. Seria o interesse na economia dos bens simbólicos, que recalca o interesse econômico, que faz com que condutas adequadas sejam aprovadas e recompensadas simbolicamente. (BOURDIEU, 1996) Prestígio social que pode se transformar em vantagens econômicas. (WEBER, 1994)

O conceito de campo burocrático articula-se e desenvolve as ideias de Weber (1982) sobre a burocracia, tipo mais puro da dominação legal. Este tipo de dominação, exercida principalmente pelo servidor do Estado, apresenta como características: ordenamento por meio de leis e normas administrativas; hierarquia na organização; impessoalidade no relacionamento; especialização de funções; separação entre os meios de administração e propriedade privada; treinamento especializado e completo; cargos com competências e atribuições claras; recrutamento por meio de critérios objetivos; livre seleção para preenchimento de cargos; promoção meritocrática; disciplina sistemática e rigorosa; e controle do cargo. (WEBER, 1982, 2003) Weber (2003) destaca a consciência burocrática, pela qual o funcionário deve administrar tudo de forma apartidária, executar as ordens dos superiores como se fossem suas convicções, mesmo 
que lhe pareçam errôneas. Aí residiria a diferença entre o burocrata e o líder político: enquanto o primeiro sacrifica as suas convicções pessoais à obediência hierárquica, o segundo caracteriza-se por assumir publicamente a responsabilidade por seus atos.

A partir do desenvolvimento da teoria weberiana, Bourdieu (2012, p. 14, tradução nossa) define inicialmente o Estado como "o monopólio da violência simbólica legítima” na medida em que este é condição necessária ao exercício da própria violência física. Para Bourdieu, o Estado seria, por excelência, um lugar de concentração e de exercício do poder simbólico e resultado de um processo de convergência de diferentes tipos de capital: de força física (instrumentos de coerção), econômico, cultural (de informação), simbólico, constituindo uma espécie de meta-capital, que lhe permitiria exercer poder sobre diferentes campos e sobre diferentes tipos de capital. O Estado estaria imbricado com o campo do poder, no qual os agentes detentores de diferentes tipos de capital lutam pelo poder sobre o Estado. (BOURDIEU, 1996, 2012)

Uma vez que o Estado resulta da concentração de diferentes tipos de capital, com poder sobre eles, e que o campo burocrático é definido como o espaço de agentes e de instituições que possuem essa espécie de metapoder (BOURDIEU, 1996, 2012), o capital burocrático foi considerado como um capital delegado pelo Estado. Apesar de Bourdieu não apresentar uma definição formal de capital burocrático, ele apresenta diversas referências pontuais que permitem compreender o seu conceito. Os agentes do campo burocrático seriam os representantes do Estado, aqueles a quem o Estado delega falar em seu nome, detentores assim de um poder garantido pelo Estado. (BOURDIEU, 2012)

A obediência às injunções estatais não se trataria de uma submissão mecânica, mas de um produto da relação dos agentes com o Estado, visto que o próprio Estado impõe as estruturas segundo as quais é percebido através, principalmente, da escola. (BOURDIEU, 1996, 2012)

A religião, assim como a escola e o Estado, contribui para manutenção da ordem estabelecida - legitimação do poder dos dominantes -, assim como para a construção de um sistema de práticas e de representações que define os princípios de estruturação da percepção e do pensamento 
de mundo. (BOURDIEU, 2005) As disposições religiosas são inculcadas e podem existir de forma inconsciente, influenciando as tomadas de posição. Nesse sentido, buscou-se também analisar a formação religiosa dos agentes.

A concentração de capital jurídico pelo Estado representa uma concentração de capital simbólico que fundamenta a autoridade específica do detentor do poder estatal, especialmente do poder de nomeação, surgindo então duas formas de acesso à nobreza: a primeira, representada pela hereditariedade e o reconhecimento público (natural); a segunda, através da nomeação Estatal, garantida pelas honrarias atribuídas pelo Estado, seja um título de nobreza, seja um título escolar. Assim, cada vez mais, o capital simbólico da nobreza deixa de ser baseado apenas no reconhecimento para encontrar uma objetivação, uma codificação, delegada e garantida pelo Estado, burocratizado, conferindo posições em virtude de capital cultural adquirido através do título escolar. (BOURDIEU, 1996, 2012)

A realização de concursos e a exigência do título seriam fatores que democratizariam a entrada nos cargos públicos, permitindo o acesso aos agentes de todas as classes, ao mesmo tempo em que poderiam favorecer por algum período a entrada das classes dominantes, devido às condições mais favoráveis para o investimento no capital escolar.

Para Bourdieu (2012), o campo burocrático é o próprio Estado, uma vez que ele é o criador e garantidor dos "fetiches" de classificação, como o título escolar, a cultura legítima, a nação, a ortografia, a noção de fronteira, entre outros. O Estado seria um "banco central de capital simbólico". (BOURDIEU, 2012, p. 196, tradução nossa)

O processo de constituição do Estado é definido por Bourdieu (1997) como um processo de “desfamiliarização", trata-se de sair da lógica familiar, doméstica, para uma outra lógica. Ou seja, o Estado opõe-se à família. Ele substitui a lealdade familiar pelas lealdades formais e condena o nepotismo. Substitui a sucessão direta e hereditária (modo de reprodução dinástico) pela reprodução de base escolar (modo de reprodução burocrático). Ocorre, então, uma tripartição do poder: entre o rei, seus irmãos e os ministros, de modo que se cria uma cadeia de controle mútuo de uns 
sobre os outros, limitando e controlando o poder de cada um. E por fim, concentra o poder de nomeação.

Para Goulart (2002, 2006), uma nova burocracia vem se estabelecendo, no âmbito da saúde, ao interior do Estado brasileiro, que denomina “executivos da saúde”. Seriam aqueles funcionários não concursados que fazem carreira ao interior desse subespaço, assumindo postos em diferentes níveis da gestão da saúde pública, tendendo mais ao perfil de funcionários políticos do que administrativos, contudo, a sua manutenção no quadro de funcionários por períodos muito longos terminaria por consagrá-los como uma espécie de quadro administrativo "atípico" que, apesar de não dispor de algumas garantias trabalhistas, gozam do mesmo prestígio e têm os mesmos ganhos secundários que os funcionários de carreira. Outrossim, acrescenta-se a esse grupo o "empreendedorismo militante", característica através da qual pessoas que ocupam posições na instituição/organização seriam capazes de promover inovações devido ao seu envolvimento emocional com o objeto, com a causa em questão, o que terminaria por congregar dedicação, criatividade e iniciativa à sua atuação. (GOULART, 2002) O conceito de empreendedorismo numa perspectiva mais sociológica, segundo Mendonça, Alves e Campos (2010), é visto como um comportamento de desvio da norma, que provavelmente não é adotado por agentes em posições dominantes, geralmente comprometidos com a reprodução e manutenção da sua posição, a não ser que essas inovações contribuam para o fortalecimento do status quo. Os agentes periféricos, ou seja, essa nova burocracia ainda não estabelecida, seriam aqueles com maior predisposição a desafiar e criar novas práticas.

O poder simbólico, conforme definido por Bourdieu (2001, p. 7-8), é um “[...] poder invisível o qual só pode ser exercido com a cumplicidade daqueles que não querem saber que lhe estão sujeitos ou mesmo que o exercem", um poder conferido por um determinado grupo a partir do reconhecimento em relação a um capital, qualquer que seja a sua espécie, transmutado em capital de reconhecimento.

Desta forma, o capital burocrático foi objetivado através dos cargos ocupados, visto que quanto mais altos os postos ocupados, maior o 
poder de delegação e maior volume de recursos sob a gestão do agente. Correspondendo também ao poder de nomeação, de controle da informação e de normalização, bem como a definição e imposição de categorias estatais legítimas.

\section{Análise da gênese ${ }^{10}$ de políticas de saúde}

A partir da definição de política de saúde proposta por Paim (2002, p. 274), como:

[...] a ação ou omissão do Estado enquanto resposta social diante dos problemas de saúde (danos e riscos) e seus determinantes bem como a intervenção sobre a produção, distribuição e regulação de bens serviços e ambientes que afetam a saúde dos indivíduos e da coletividade.

Analisar a gênese de uma política de saúde, é buscar compreender o contexto político, cultural e social que determinou a necessidade de intervenção do Estado para a implementação de medidas específicas de controle de um determinado problema de saúde, ou seja, quais foram as condições que possibilitaram o reconhecimento de um determinado agravo à saúde como um problema social que exigia uma resposta governamental específica.

A seleção das categorias analíticas foi baseada na proposta de Pinell (2010) a partir do estudo da gênese de quatro políticas de saúde na França - política em favor da infância anormal, política de luta contra a toxicomania, política de luta contra o câncer e política de luta contra a aids. Os estudos de Pinell tinham a política como pano de fundo de um problema objeto de estudo sociológico, de modo que o autor realizou um esforço inverso ao da maioria dos pesquisadores de ciências políticas, analisando a política a partir do referencial teórico sociológico bourdieusiano, mas sem uma teoria prévia a ter sua pertinência verificada pela análise de caso. A posteriori,

10 O termo gênese é compreendido como origem, como conjunto de fatos ou elementos que concorrem para a formação de alguma coisa e o termo emergência é usado como seu sinônimo. 
Pinell (2010) elaborou proposições acerca dos processos comuns à emergência das políticas por ele estudadas na sua gênese e evolução.

Para a emergência de uma política pública de saúde, identificou:

1. O reconhecimento pelo poder público da necessidade de medidas específicas para o enfrentamento de um determinado problema que não tem solução satisfatória no âmbito das instituições e/ou leis existentes;

2. A responsabilização do Estado a partir da identificação de um problema já existente e da inadequação das políticas de organização e/ ou das práticas institucionais existentes;

3. A necessidade de alianças entre os diferentes grupos sociais interessados no reconhecimento de determinado problema, construindo uma definição comum do problema, apesar dos diferentes pontos de vista sobre o que é o problema ou sobre as medidas a serem tomadas;

4. A negociação para a definição de uma visão comum do problema pode levar a conflitos, a uma luta simbólica pela definição do problema e suas consequências, haja vista a concorrência aparentemente irredutível entre os grupos com interesse em construir o problema social;

5. A definição do problema constrói-se pela dinâmica de um jogo social, como produto da interpenetração das estratégias dos diferentes grupos de agentes interessados em construírem o problema como um problema social. Nesse contexto, a definição será tanto mais precisa - e restrita - quanto mais forte a concorrência entre os grupos de agentes e tanto mais imprecisa quanto os grupos interessados não são concorrentes;

6. Quando os grupos chegam a superar seus eventuais conflitos de interesse, a lógica para a elaboração de um projeto comum não é o acordo sobre uma definição precisa do problema e de suas soluções, mas de produzi-las de forma suficientemente ambíguas para não evidenciar eventuais contradições; 
7. A definição do problema e das soluções construídas antes do reconhecimento do problema pelo Estado leva a remodelações quando tem início a formulação da política específica pelos poderes públicos. A definição e a implantação de uma nova política levam a necessidade de ajustamento das políticas, instituições e estruturas já existentes. Isso se deve ao fato de que:

a. A expansão ou a criação de um novo espaço social com suas questões simbólicas, institucionais, profissionais e materiais em jogo tende a modificar os equilíbrios pré-existentes no mundo social;

b. A pressão sobre os poderes públicos de apresentar a nova política como uma expressão do interesse coletivo.

Com relação à evolução das políticas, a implantação e a evolução de uma política de saúde são produtos da dinâmica de um jogo social complexo que deve considerar:

1. As evoluções tanto de ordem médica - epidemiologia e conhecimento médico sobre a doença, técnicas, tratamentos -, como de ordem social - alterações na mobilização contra a doença;

2. Os efeitos concretos da implantação da política - novas instituições, desenvolvimento de grupos profissionais, emergência de novas estruturas associativas - e os obstáculos encontrados;

3. As mudanças de governo, sendo possível a manutenção ou a mudança da maioria política;

4. As mudanças independentes da política que afetam as instituições do campo médico - reformas hospitalares, estudos médicos - ou de outros campos implicados naquela política - educação, justiça etc. - e mais globalmente toda a sociedade - guerras ou mudanças de costumes e nas formas de controle social. (PINELL, 2010) 